\title{
Uma nova espécie de Centris Fabricius (Hymenoptera, Apoidea, Anthophoridae) do Nordeste do Brasil ${ }^{1}$
}

\author{
Jesus Santiago Moure ${ }^{2}$ \\ Marina Siqueira de Castro ${ }^{3}$
}

\begin{abstract}
A new species of Centris Fabricius (Hymenoptera, Apoidea, Anthophoridae) from Northeastern Brazil. A new species of Centris Fabricius, 1804 is described as $C$. xanthomelaena (body size $15 \mathrm{~mm}$, forewing length $10.33 \mathrm{~mm}$, head width $5.25 \mathrm{~mm}$, second abdominal tergum width $5.75 \mathrm{~mm}$ ). The specimens were captured when visiting the yellow flowers of Chamaecrista amiciela (I. \& B.) I. \& B., Caesalpiniaceae and of Stimaphyllom auriculatum (Cav.) Adr. Juss, Malpighiaceae. KEY WORDS. Hymenoptera, Apoidea, Centridini, Centris
\end{abstract}

O gênero Centris Fabricius, 1804 abrange abelhas de tamanho moderado a grande, comuns nos trópicos (MICHENER et al. 1994). Estas abelhas são importantes polinizadoras de vários grupos de plantas de ecossistemas naturais e agrícolas, principalmente das famílias fornecedoras de óleo. Os espécimens examinados foram coletados durante um estudo sobre a comunidade de Apoidea, realizado no período de setembro de 1996 a fevereiro de 1999, em Milagres ( $12^{\circ} 53^{\prime} \mathrm{S}$ e $\left.39^{\circ} 51^{\prime} \mathrm{W}\right)$, semi-árido do estado da Bahia, cidade situada a $395 \mathrm{~m}$ de altitude, com temperatura média anual de $24,9^{\circ} \mathrm{C}$, umidade relativa média anual de $67 \%$ e precipitação de $481 \mathrm{~mm}$.

As coletas de campo foram realizadas na fazenda "Bastião" e os espécimens foram capturados nas flores amarelas de Chamaecrista amiciela (I. \& B.) I. \& B. (Caesalpiniaceae), um pequeno subarbusto de aproximadamente $30 \mathrm{~cm}$ e de Stigmaphyllon auriculatum (Cav.) Adr. Juss (Malpighiaceae), uma trepadeira de flores amarelas. Um dos espécimens capturados encontrava-se com pólen na escopa. Foram capturadas outras espécies do gênero Centris visitando as flores de Chamaecrista amiciela: Centris (Centris) caxiensis Ducke, 1907, Centris (Paremisia) fuscata Lepeletier, 1841 e Centris (Hemisiella) tarsata Smith, 1874; e de Stigmaphyllom auriculatum: Centris (Centris) aenea Lepeletier, 1841, na caatinga em Milagres, Bahia.

As medidas foram feitas com ocular micrométrica em microscópio estereoscópio Wild M5. A referência ao tamanho dos intervalos entre os pontos é dada pelo diâmetro do ponto (dp), assim, " 2 dp" correspondem a dois diâmetros

1) Contribuição número 1255 do Departamento de Zoologia, Universidade Federal do Paraná.

2) Departamento de Zoologia, Universidade Federal do Paraná. Caixa Postal 19020, 81531-990 Curitiba, Paraná, Brasil. Bolsista do CNPq. E-mail: urban@bio.ufpr.br

3) Central de Laboratórios da Agropecuária, Empresa Baiana de Desenvolvimento Agrícola. Avenida Ademar de Barros 967, Ondina, 40170-110 Salvador, Bahia, Brasil. Bolsista CAPES. E-mail: marina@e-net.com.br 
de ponto. Outras abreviaturas do texto são: $\mathrm{T}$ e $\mathrm{E}$, que indicam tergos e esternos, respectivamente, e quando seguidos de um número como "T2" = segundo tergo; F significa flagelômero. As medidas, quando sem outra indicação, correspondem a centésimos de milímetros.

\section{Centris (Paracentris) xanthomelaena sp. $\mathbf{n}$. Figs 1-4}

Fêmea. Comprimento total aproximado $15,0 \mathrm{~mm}$; comprimento da asa anterior $10,33 \mathrm{~mm}$; largura da cabeça $5,25 \mathrm{~mm}$; largura do segundo tergo abdominal $5,75 \mathrm{~mm}$.

Tegumento preto sem desenhos amarelos, exceto uma pequena mancha anterior nos dois terços apicais da mandíbula. As tégulas castanho-claro marginadas de branco. As asas bastante hialinas, um pouco mais escurecidas na parte apical devido às papilas bem desenvolvidas.

Pilosidade amarela, com tonalidade esverdeada típica na cabeça, tórax, flancos do propódeo e base do T1; no terço inferior das genas esbranquiçada. Alguns pêlos castanho-escuros na região anterior próxima aos ocelos; no labro branca com algumas cerdas pretas na extremidade apical; no clípeo amarela com alguns pêlos brancos no disco deixando uma estria glabra. Nos mesepisternos amarela até o nível das coxas, e preta na face ventral. $\mathrm{Na}$ extremidade basal de T1, uma faixa de pêlos amarelos, alargada nos lados, o pêlos mais compridos na concavidade basal e nos lados de T1; a metade apical de T1 e o restante o abdome preto-pilosos, com pêlos curtos nos tergos e mais longos na franja do bordo posterior do esternos, e na região mediana de E2; em T1 a T5 a pilosidade não cobre o tegumento, sendo mais esparsa no disco de T3 e T4, com margem apical estreitamente lisa e brilhante. T5 com estreita franja apical preta. Todas as pernas inteiramente preto pilosas exceto alguns pêlos branco-amarelentos na parte inferior dos fêmures anteriores.

Pontuação fina e pilígera. Na área glabra do clípeo um pouco mais grossa com alguns pontos anastomosados deixando os intervalos micro-reticulados e transversos, careniformes; um pouco irregulares nos $2 / 3$ basais da estria média; ao longo do meio, os intervalos maiores até $4-5 \mathrm{dp}$ com um vermiculado transversal na parte média. $\mathrm{Na}$ base do labro mais forte e os pontos um pouco mais grossos com intervalos reticulados. No tórax coberta pela pilosidade. No resto do corpo a pontuação um pouco mais esparsa com intervalos brilhantes entre os pontos, cerca de 2-3 dp na base de T2; mais finos e mais numerosos em T1 e T2; no disco do T3 e T4 mais esparsos que em T2. Na área basal do propódeo uma depressão média, tendo pontos bem diferenciados de 2-3 dp; para os lados a pontuação quase nula e a superfície reticulada. Nos intervalos finamente reticulada; em E2 e E3 muito fina e bastante densa para os lados, no disco muito grossa e mais esparsa, característica interessante.

Estrutura e Proporções. A cabeça mais larga que longa (comprimento 2,5 $\mathrm{mm}$ e largura 5,25 mm). Olhos: comprimento e largura (336:180); distância interorbital superior, máxima e inferior: 144:292:240, menores que o comprimen- 

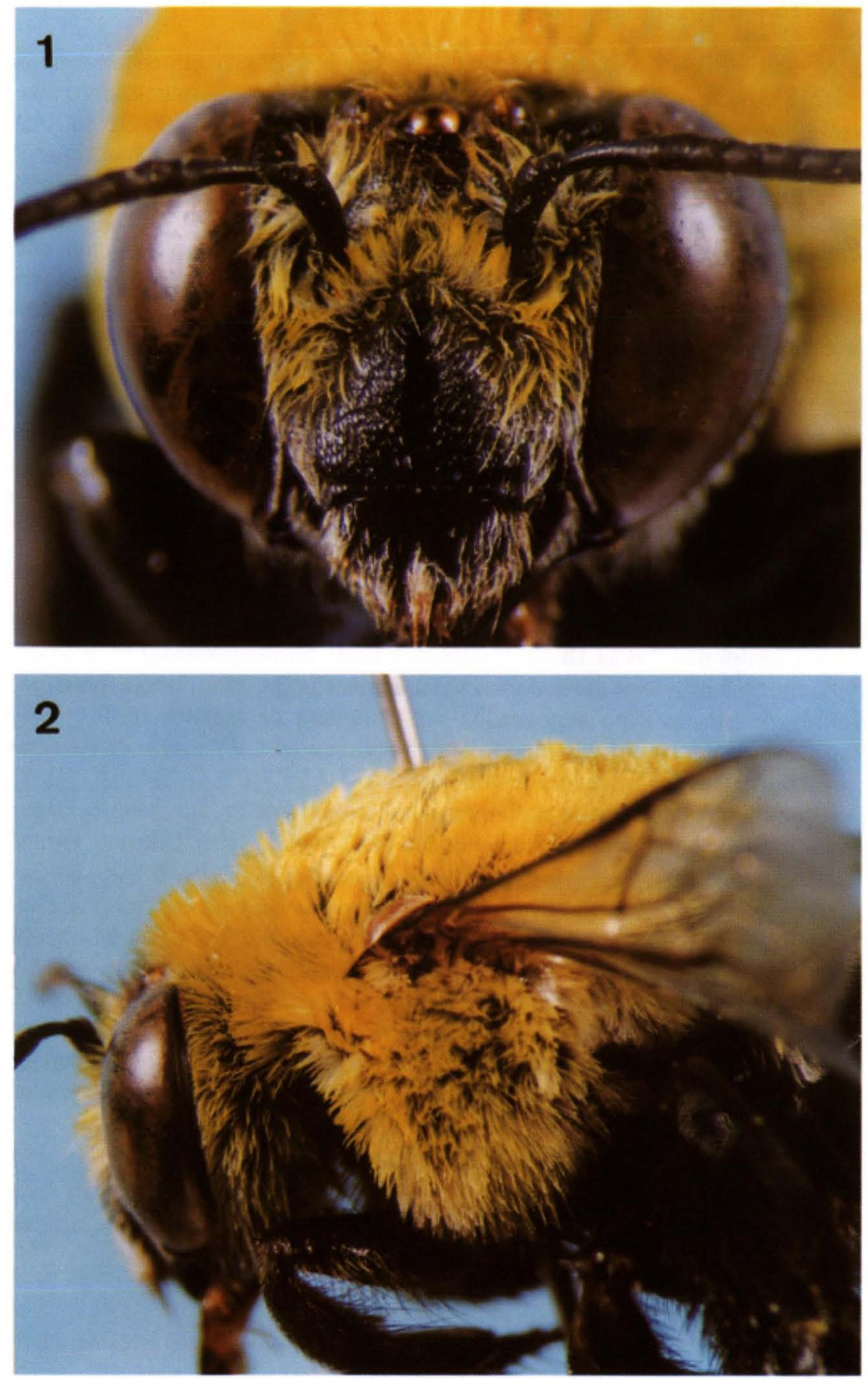

Figs 1-2. Centris xanthomelaena sp.n., holótipo fêmea. (1) Cabeça em vista anterior, (2) cabeça e tórax em vista lateral. 
to do olho. Clípeo com comprimento, largura e distância clipeocelar, como 105:228: 160. Carena frontal fina e curta no terço inferior. Distâncias interalveolar, alveolorbital, alveolocelar e diâmetro do alveolo, como 92:48:92:30. Interocelar, ocelorbital e diâmetro do ocelo médio, como 88:56:48. A gena, de perfil, ligeiramente mais larga que o olho; sem carena preoccipital. Distância clipeorbital estreita e área malar linear. Clípeo não muito elevado. Mandíbula longa, quadridentada; o terceiro dente mais para trás que os outros. Palpos maxilares com quatro artículos. Largura e comprimento do labro (160:100). Diâmetro e comprimento do escapo (28:80). O artículo basal do flagelo com comprimento menor que seu diâmetro; F2 e F3 com diâmetros iguais. Comprimento do $1^{\circ}, 2^{\circ}$ e $3^{\circ}$ artículos do flagelo e diâmetro do $3^{\circ}$ flagelômero: $24: 32: 32$ e 32 . Comprimento do $1^{\circ}, 2^{\circ}, 3^{\circ}$ e $4^{\circ}$ artículos dos palpos maxilares: 40:80:52:20. A placa basitibial com parte basal engrossada e recortada em forma de $\mathrm{S}$ imperfeito; a superior como que dobrada sobre a inferior em forma de pingo ou lágrima invertida e jogada para o lado; a inferior ogival, com a superfície excepcionalmente brilhante se comparada com a da superior. Placa pigidial bastante gasta, aparentemente dupla. Pernas inermes.

Material tipo. Holótipo e dois Parátipos fêmeas. BrasiL, Bahia: Milagres, em 28-I-1998 Marina Siqueira de Castro leg., coletados em Chamaecrista amiciela (Caeslpiniaceae) às 10:50 (holótipo) e 10:45 horas (parátipo) e em 31-III1997 em Stimaphyllom auriculatum (Malpighiaceae) às 10:30 horas (parátipo). Holótipo e um parátipo depositados sob o número de registro 1070 e 1069 , respectivamente, na coleção entomológica regional do Laboratório de Abelhas, Empresa Baiana de Desenvolvimento Agrícola (LABE/EBDA), Salvador, Bahia e um parátipo foi depositado na Coleção de Entomologia Pe. J.S. Moure, Departamento de Zoologia, Universidade Federal do Paraná (DZUP), Curitiba, Paraná.

Comentários. Exemplares desta espécie, enviados pelo Dr. S. Vogel, foram identificados como espécie nova por J.S. Moure que a nomeou Centris (Paracentris) xanthomelaena. Entretanto, este nome foi citado por VoGEL \& MACHADO (1991: 163-167, 169, 170, 174-175), antes de sua publicação; porém, no referido trabalho, os autores assumem que a espécie possivelmente ainda não havia sido descrita, e que o nome Centris xanthomelaena estava sendo utilizado provisoriamente, citando-o sempre entre aspas (... and an indeterminable, possibly undescribed species of subg. Paracentris, here provisionally named $C$. "xanthomelae$n a " .$.$) .$

Etimologia. O nome da espécie faz referência ao padrão de cores da pilosidade do tórax.

Distribuição geográfica. Endêmica da região semi-árida do nordeste brasileiro.

AGRADECIMENTOS. À D. Olga Ávila Ribeiro, Sr. Raul Ribeiro e Luiza Ávila por nos disponibilizar a fazenda "Bastião", para as coletas de abelhas. Ao técnico José Xavier de Jesus (da EBDA), pela valiosa ajuda durante as coletas de campo. À CAPES e ao CNPq pela concessão das bolsas. À EBDA pelo financiamento das viagens de campo. 

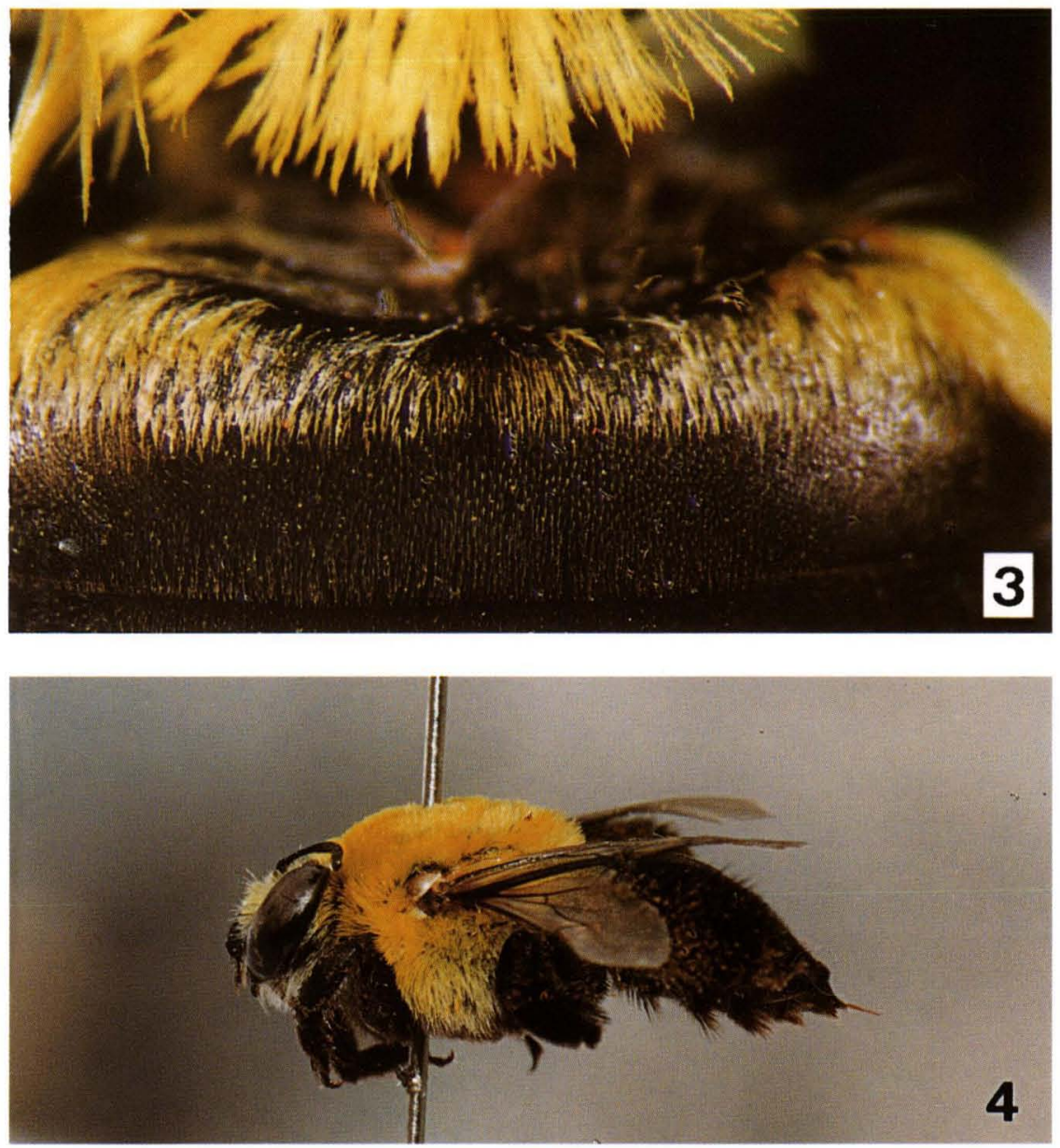

Figs 3-4. Centris xanthomelaena sp.n., holótipo fêmea. (3) Primeiro tergo; (4) vista lateral.

\section{REFERÊNCIAS BIBLIOGRÁFICAS}

Michener, C.; R.M.C. Ginley \& B.N. Danforth. 1994. The bee Genera of North and Central America (Hymenoptera: Apoidea). Washington, D.C., Smithsonian Institution Press, 202p.

VOGEI., S.\& I.C. MACHADO. 1991. Pollination of four sympatric species of Angelonia (Scrophulariaceae) by oil-collecting bees in NE. Brazil. PI. Syst. Evol. 178: 153-178. 